\title{
FIGO Stage IIIA1(ii)
}

National Cancer Institute

\section{Source}

National Cancer Institute. FlGO Stage IIIA1(ii). NCI Thesaurus. Code C128104.

A FIGO stage term that applies to ovarian cancer, fallopian tube cancer, and primary peritoneal cancer. It refers to cancer with positive retroperitoneal lymph nodes only. Metastasis greater than $10 \mathrm{~mm}$. 